\title{
Characterization of Native Alginates of Common Alginophytes from the Red Sea Coast of Sudan
}

\author{
Nahid Abdel Rahim Osman 1,*, Tasneem Omer Suliman², Khadega Ahmed Osman'
}

${ }^{1}$ Faculty of Marine Science and Fisheries, Red Sea University, Port Sudan, Sudan

${ }^{2}$ Marine Fisheries Administration, Ministry of Agriculture, Red Sea State, Port Sudan, Sudan

\begin{abstract}
The objective of this investigation was to investigate the content, viscosity, and major functional groups of the native alginates extracted from 4 alginophytes collected from the Red Sea coast of Sudan in order to evaluate the quality of the polymer for potential applications. The content of the polymer ranged from $7.99 \pm 2.60 \%$ to $19.1 \pm 1.62 \%$ based on dry weight in the 4 seaweeds. The peak characteristics of the major functional groups of alginates were identified between $3469.70 \mathrm{~cm}^{-1}$ to $451.31 \mathrm{~cm}^{-1}$. These peaks specify the presence of hydroxyl $(\mathrm{OH})$, carbonyl $(\mathrm{C}=\mathrm{O})$, and carboxyl $(\mathrm{COOH})$ groups, respectively. The $\mathrm{M} / \mathrm{G}$ ratios of the alginate extracted from the Sudanese brown macroalgae are $\leq 1$ indicating that the proportion of guluronic acid is slightly greater than the mannuronic acid. The alginate with highest viscosity was that of Padina pavonica (Linnaeus) Thivy (190.7 $\pm 1.14 \mathrm{mPa} . \mathrm{s})$ followed by Dictyota dichotoma (Hudson) J.V.Lamouroux (146.96 $\pm 1.2 \mathrm{mPa} . \mathrm{s})$, Turbinaria ornata (Turner) J.Agardh (140.1 $\pm 1.14 \mathrm{mPa} . \mathrm{s})$, and Hormophysa cuneiformis (J.F.Gmelin) P.C.Silva (109 $\pm 0.6 \mathrm{mPa} . \mathrm{s})$. The values of the parameters of the native alginates extracted from the Sudanese macroalgae are comparatively in conformity with values reported for some species from similar geographical regions. These values indicated that the present biopolymer is of a potential with regard to pharmaceutical and industrial applications.
\end{abstract}

\section{ARTICLE HISTORY}

Received: February 09, 2020

Revised: March 14, 2020

Accepted: December 18, 2020

\section{KEYWORDS}

Alginates,

M/G ratio,

Viscosity,

Red Sea,

Sudan

\section{INTRODUCTION}

Brown macroalgae or Phaeophyta are almost entirely marine macroalgae. While they are the predominant macroalgae in the intertidal and subtidal zones of temperate to Polar Regions, they comparatively become less prominent at lower latitudes of the tropics. In the Red Sea coast of Sudan brown macroalgae are commonly conspicuous on the subtidal zone towards the reef flats in patchy distribution pattern.

Brown macroalgae are rich in bioactive metabolites such as polysaccharides, polyphenols, and terpenes. Polysaccharides or hydrocolloid polysaccharides are a class of macromolecules present primarily in the cell walls of marine macroalgae with varying composition according to the season, age, species, and geographic location [1]. Brown seaweeds are known to produce different polysaccharides, like the polymer group of alginates,

CONTACT: Nahid Abdel Rahim Osman $\square$ nahidcoast@yahoo.com $\equiv$ Faculty of Marine Science and Fisheries, Red Sea University, Port Sudan, Sudan 
fucoidans, and laminarans. Laminarans and fucoidans are the main water-soluble polysaccharides of brown algae whereas the high-molecular mass alginates group is alkali soluble polysaccharides. Alginates perform vital functions pertinent to brown seaweeds biological integrity. They act as a food reserve and provide strength and flexibility to the plant to withstand wave action and maintain ionic equilibrium in the cell. The homogeneity of their structures promotes interaction with external ions and inter-chain hydrogen bonding (e.g. gelation). Of the polysaccharides of the brown macroalgae, the gel forming biopolymers alginates are very important economically and industrially [2]. The most common applications of alginates are in food, cosmetics, medical, and pharmaceutical industries where it is used as stabilizer and thickener, as wound dressings, and as matrices to encapsulate and/or release cells and medicine [3]. Emerging studies have reported that alginates have some biological activities $[4,5]$ that may include immune-stimulation, prevention of chemically induced carcinogenesis and ulcerogenes, obesity control, and lowering of blood sugar and cholesterol level. Further, alginate has recently utilized in the field of tissue engineering [6-8].

Alginates have also been utilized in heavy-metal and toxic materials adsorption, in paper, textile, and food packages industries [9]. Alginates are groups of more than 200 compounds with common yet subtle variations in their physicochemical properties. Alginate is a linear copolymer made up of sequences or blocks of mannuronic acid (M-block), guluronic acid (Gblock), and $\mathrm{M}$ and $\mathrm{G}$ blocks that coexist in different proportions and patterns in the alginate of the different species of brown macroalgae. The composition and distribution pattern of M-block and G-block are the factors responsible for the physicochemical properties of alginates' such as viscosity, sol/gel transition, and water-uptake ability [5]. Alginate with more G-block composition produces stronger, mechanically stable, and brittle gels, while that with more Mblock forms soft and elastic gels.

The utilization of alginates in a particular use is dependent on the physicochemical properties of the polymer such as viscosity of the polymer in water solution and gelation. Alginate with high viscosity is considered of high quality compared to those of low viscosity. It has been proven that alginate with more proportion of $\mathrm{G}$ units has physicochemical properties suitable for industrial applications, while the alginate with more mannuronic acid units is suitable for pharmaceutical and environmental applications. The ratio of mannuronic acid to guluronic acid (M/G ratio) is used to infer the proportions of $\mathrm{M}$ and $\mathrm{G}$ in the alginate. This ratio is estimated from the FT-IR spectrum of the alginate with the wavelengths that characterize these acids. The $\mathrm{M} / \mathrm{G}$ ratio, although the number and size of blocks are not provided, provides a practical estimate to evaluate the suitability of alginate for a particular use [10].

The objective of this investigation was to characterize the native alginates of 4 common brown macroalgae present along the Sudanese Red Sea coast with regard to yield, viscosity, and $\mathrm{M} / \mathrm{G}$ ratio in order to evaluate its applicability.

\section{MATERIAL and METHODS}

\subsection{Seaweeds Materials}

The healthy and fully grown thalli of the brown seaweeds Dictyota dichotoma, Hormophysa cuneiformis, Padina pavonica, and Turbinaria ornata were collected from the Sudanese Red Sea coast north of Port Sudan city. The samples were thoroughly washed in situ with seawater to remove siltation and epiphytes. In the laboratory the samples were cleaned and washed with fresh water and distilled water to further remove salt and extraneous materials. Subsequently, the materials were spread in the shade to be air-dried. Then, the dry mass of macroalgae mass was ground to a homogenous powder and kept in airtight containers at $4^{\circ} \mathrm{C}$ until further use. 


\subsection{Determination of Moisture Content}

The moisture content of the seaweed materials was determined gravimetrically according to AOAC [11].

\subsection{Determination of Alginate Intrinsic Viscosity}

The viscosity of $1 \% \mathrm{w} / \mathrm{v}$ alginate aqueous solution of $\mathrm{pH}$ around 3 to $3.5 \mathrm{was}$ measured at room temperature with digital rotary viscometer (Zhengji, DNJ-5S) with due consideration to the manufacturer's guidelines.

\subsection{Characterization of Sodium Alginate by Fourier Transform Infra Red}

The sodium alginates of the 4 brown macroalgae were examined with Fourier Transform Infra Red (FT-IR) spectroscopy (Shimadzu, FT-IR 8400S). Small portion of the alginate was mixed with potassium bromide and compressed into a firm disc for the FT-IR examination. The spectra were obtained in transmission mode in the range of 400 to $4000 \mathrm{~cm}^{1}$ and were the average of 2 measurements undertaken at a resolution of $2 \mathrm{~cm}^{-1}$ and 40 scans. The ratio of the mannuronic acid to guluronic acid $(\mathrm{M} / \mathrm{G})$ in the native sodium alginate extracted in this investigation was determined based on the infrared spectra. The absorbance at the wave number $1100 \mathrm{~cm}^{-1}$ corresponding to the mannuronic acid and at the wave number $1125 \mathrm{~cm}^{-1}$ corresponding to the guluronic acid was determined with the most probable baseline method [13] and the equation:

$\mathrm{A}=2-\log \mathrm{T}$ where $\mathrm{A}$ is the absorbance and $\mathrm{T}$ is the transmission.

\section{RESULTS and DISCUSSION}

The content and viscosity of sodium alginate in D. dichotoma, H. cuneiformis, $P$. pavonica, and T. ornata are given in Table 1 . The highest content of alginate was obtained from $H$. cuneiformis $(19.1 \pm 1.62 \%)$ and $T$. ornata $(14.3 \pm 1.2 \%)$ respectively. These two algae belong to the same order Fucales. Comparatively, lower content of alginate was obtained from $D$. dichotoma $(8.8 \pm 2.12 \%)$ and P. pavonica $(7.99 \pm 2.60 \%)$ that belong to the order Dictyotales.

Table 1. Content and viscosity of sodium alginate in D. dichotoma, H. cuneiformis, P. pavonica, and T. ornata from Sudan.

\begin{tabular}{lccc}
\hline No & Species name & Content of alginate (\%) & Viscosity (mPa-s) \\
\hline 1 & Dictyota dichotoma & $8.8 \pm 2.12$ & $146.96 \pm 1.2$ \\
2 & Hormophysa cuneiformis & $19.1 \pm 1.62$ & $109 \pm 0.6$ \\
3 & Padina pavonica & $7.99 \pm 2.60$ & $190.73 \pm 1.14$ \\
4 & Turbinaria ornata & $14.3 \pm 1.2$ & $140 \pm 1.14$ \\
\hline
\end{tabular}

The value of the alginate content of the present $D$. dichotoma is different from that obtained for the same species from the Egyptian coast (22.9\% to 20.9\%) as recorded in Deyab et al. [14]. The difference in the yield could be attributed to the longer extraction time ( $3 \mathrm{hrs}$ ) and the high temperature $\left(100^{\circ} \mathrm{C}\right)$ employed during the extraction of the Egyptian species or to the acidic treatment of the algal mass before extraction. It is worth to mention that the alginate content of the Dictyotales from the Sudanese Red Sea coast (D. dichotoma and P. pavonica) is comparable to its content in Dictyotales from the Mexico coast as reported in García-Ríos et al. [15] where it was $7.4 \pm 1.1 \%$ for Dictyota caribaea Hörnig \& Schnette and 5.4 $\pm 0.2 \%$ for Padina perindusiata Thivy.

On the other hand, some of the values of alginate content of the 4 brown macroalgae could relatively be considered in conformity with those reported for some tropical brown macroalgae. For instance, the alginate content of a Sargassum species, ranged from $12 \%$ to $16.5 \%$ when the 
alga was treated with an acidic solution prior to the extraction [16]. However, the yield of alginate of the same alga increased remarkably to $25-30 \%$ when the alga was treated with alkali solution before the extraction was performed.

The content of alginate of the present T. ornata $(14.3 \%)$ is congruent with that of the same species from Indonesia (13.33\%) recorded in Widyastuti [17]. Also, the content of alginate in Turbinaria decurrens Bory was $14.2 \%$ [18] similar to the value obtained for the T. ornata in this investigation. Nevertheless, the alginate content of the former alga fluctuates from $9.6 \%$ to $16.9 \%$ when the algal mass was treated with different concentrations of formalin ( $2 \%$ to $40 \%$ ). It is worth to mention that the lower concentrations of the formalin $(2 \%$ and $10 \%)$ as well as the highest concentration (30\% to $40 \%$ ) produced lower amount of alginate compare to the control sample (14.2\%). The alginate content in Hormophysa triquetra (C.Agardh) Kützing extracted for 1 hour time was $19.20 \%$ relatively similar to the present value of alginate content in $H$. cuneiformis. Relatively higher amount of alginate (12.4\%) were reported for Padina tetrastromatica Hauck than that reported here for P. pavonica $(7.99 \%)$.

It was reported that the yield of alginate increases with the increase in alkali concentration, the time of extraction, and the pretreatment of the algal materials with acids $[16,18]$. In line with this, the yield of sodium alginate extracted from Sargassum species (Fucales) ranged from a minimum of $12.13 \%$ to $30.1 \%$ due to application of different extraction methods [16]. However, acid pre-treatment of the algal mass before the alkali extraction of the alginate has been reported to reduce the viscosity of the alginate [19]. Therefore, acid treatment step of the algal mass was not performed in this investigation. The alginate yield of the present brown macroalgae is anticipated to increase with the increase of the time and temperature of the extraction.

The results obtained in this investigation and those of Garcia-Rios et al. [15] may indicate that members of the Fucales comparatively contain more alginates than Dictyotales. The viscosity of the sodium alginate extracted in this study ranged from a lowest value of $109 \pm 0.6$ $\mathrm{mPa}$-s for H. cuneiformis to a highest value of 190.7.2 $\pm 1.14 \mathrm{mPa}$-s for $P$. pavonica (Table 1). It's noteworthy to mention that the alginate of $H$. cuneiformis, which has produced the highest yield of alginate in this study, has the lowest viscosity. It has been reported that alginate has a wide range of viscosity. The viscosities of $1 \% \mathrm{w} / \mathrm{v}$ aqueous solutions of different types of sodium alginate have dynamic viscosities starting from 20 to $400 \mathrm{mPa} \cdot \mathrm{s}$ at $20^{\circ} \mathrm{C}[5,20]$. The values of the viscosity of the alginates extracted in this investigation are normal and within the known rage of the biopolymer viscosity.

The viscosity of alginates is dependent on the molecular weight of the polymer, the content of uronic acids, and the $\mathrm{pH}$ during the extraction process [10]. Alginates with high molecular weight and high guluronic acid content are more viscose. Therefore, it might be possible to infer that alginates from the tested species have low to intermediate molecular weight. Nevertheless, alginates with high viscosities were obtained under controlled extraction condition particularly on commercial scale. For instance, manipulation of the temperature, $\mathrm{pH}$, and time of extraction produces alginates with high or low viscosity. Further, alginates with low viscosity are preferred for use in pharmaceutical industry in controlled-release drug delivery system [21] among other applications as they form softer hydrogels. Accordingly, based on the present values of the viscosity, the alginate of the investigated species might be suitable for pharmaceutical application taking into consideration that other prerequisites are also met. Typical FT-IR spectrum of sodium alginate shows absorption bands at 3390, 2930, $1615,1410,1320,1300,1170,1150,1125,1090,1035,950,900,890,815$ and $780 \mathrm{~cm}-1$. The FT-IR spectra of the alginate obtained from the 4 Sudanese brown macroalgae are shown in Figures 1, 2, 3 and 4. The FT-IR spectra of D. dichotoma alginate (Figure 1) showed strong to medium bands at $3419.56 \mathrm{~cm}^{-1}, 2921.96 \mathrm{~cm}^{-1}, 1616.24 \mathrm{~cm}^{-1}, 1415.65 \mathrm{~cm}^{-1}, 1126.35 \mathrm{~cm}^{-1}$, 
$1091.63 \mathrm{~cm}^{-1}, 1031.85 \mathrm{~cm}^{-1}, 946.88 \mathrm{~cm}^{-1}, 877.56 \mathrm{~cm}^{-1}, 838.98 \mathrm{~cm}^{-1}, 790.76 \mathrm{~cm}^{-1}$, and weak bands at and $821.62 \mathrm{~cm}^{-1}$ and $1265.22 \mathrm{~cm}^{-1}$.

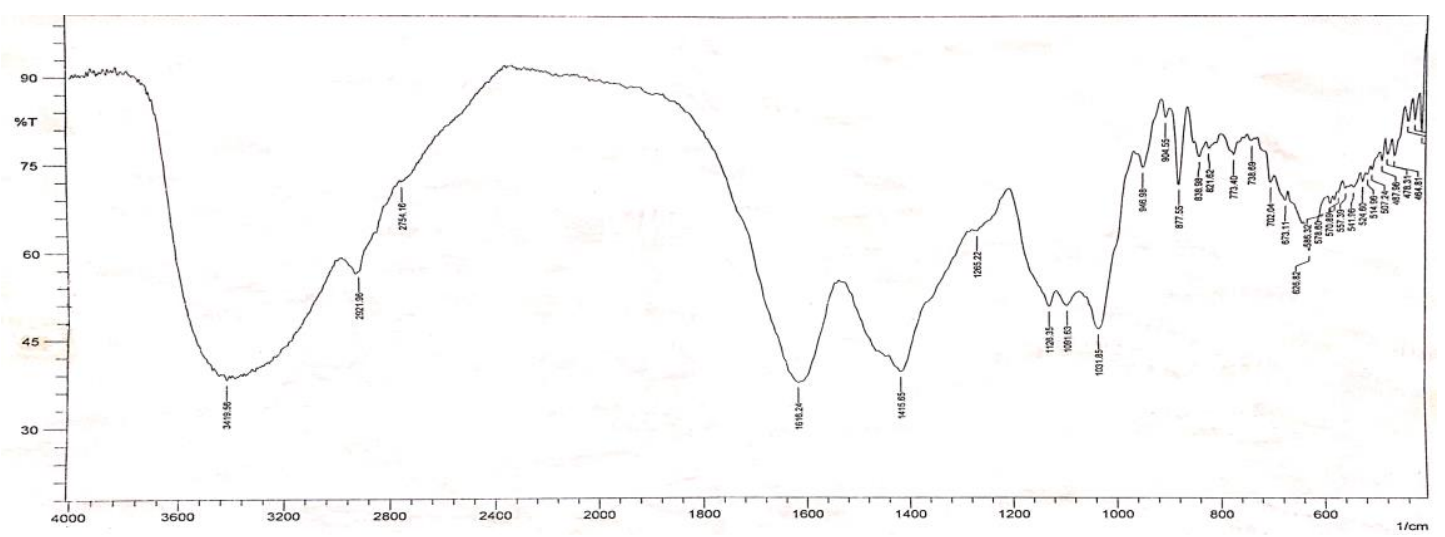

Figure 1. The FT-IR spectrum of the sodium alginate of $D$. dichotoma (Sudan, Red Sea coast)

The strong and medium bands of $H$. cuneiformis alginate FT-IR spectrum (Figure 2) occured at $3469.70 \mathrm{~cm}^{-1}, 2921.96 \mathrm{~cm}^{-1}, 1728.10 \mathrm{~cm}^{-1}, 1639.38 \mathrm{~cm}^{-1}, 1458.08 \mathrm{~cm}^{-1}, 1377.08 \mathrm{~cm}^{-}$ $1,1141.78 \mathrm{~cm}^{-1}, 1027.99 \mathrm{~cm}^{-1}, 948.91 \mathrm{~cm}^{-1}, 840.91 \mathrm{~cm}^{-1}, 790.76 \mathrm{~cm}^{-1}$, and $610.11 \mathrm{~cm}^{-1}$.

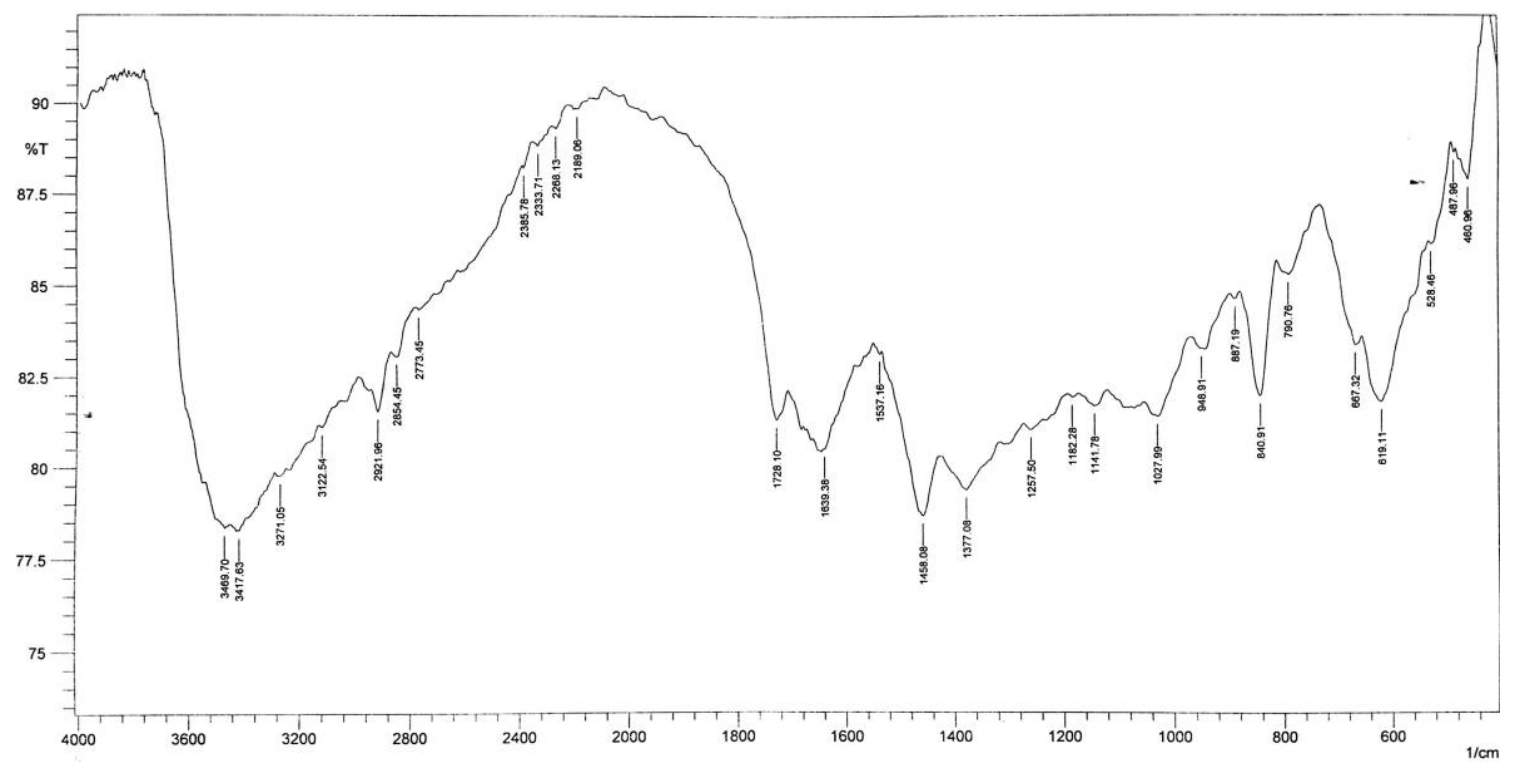

Figure 2. The FT-IR spectrum of the sodium alginate of H. cuneiformis (Sudan, Red Sea coast)

Almost all the bands of $P$. pavonica alginate FT-IR spectrum were strong and broad (Figure 3). They were recorded at $3382.91 \mathrm{~cm}^{-1}, 2927.74 \mathrm{~cm}^{-1}, 1728.17 \mathrm{~cm}^{-1}, 1616.17 \mathrm{~cm}^{-1}$, $1458.08 \mathrm{~cm}^{-1}, 1407.94 \mathrm{~cm}^{-1}, 1124.42 \mathrm{~cm}^{-1}, 1093.56 \mathrm{~cm}^{-1}, 1029.92 \mathrm{~cm}^{-1}, 946.98 \mathrm{~cm}^{-1}$, and $636.27 \mathrm{~cm}^{-1}$. In additions, bands at $904.55 \mathrm{~cm}^{-1}, 875.62 \mathrm{~cm}^{-1}, 850.55 \mathrm{~cm}^{-1}, 840.91 \mathrm{~cm}^{-1}, 821.62$ $\mathrm{cm}^{-1}$ were also detected. 


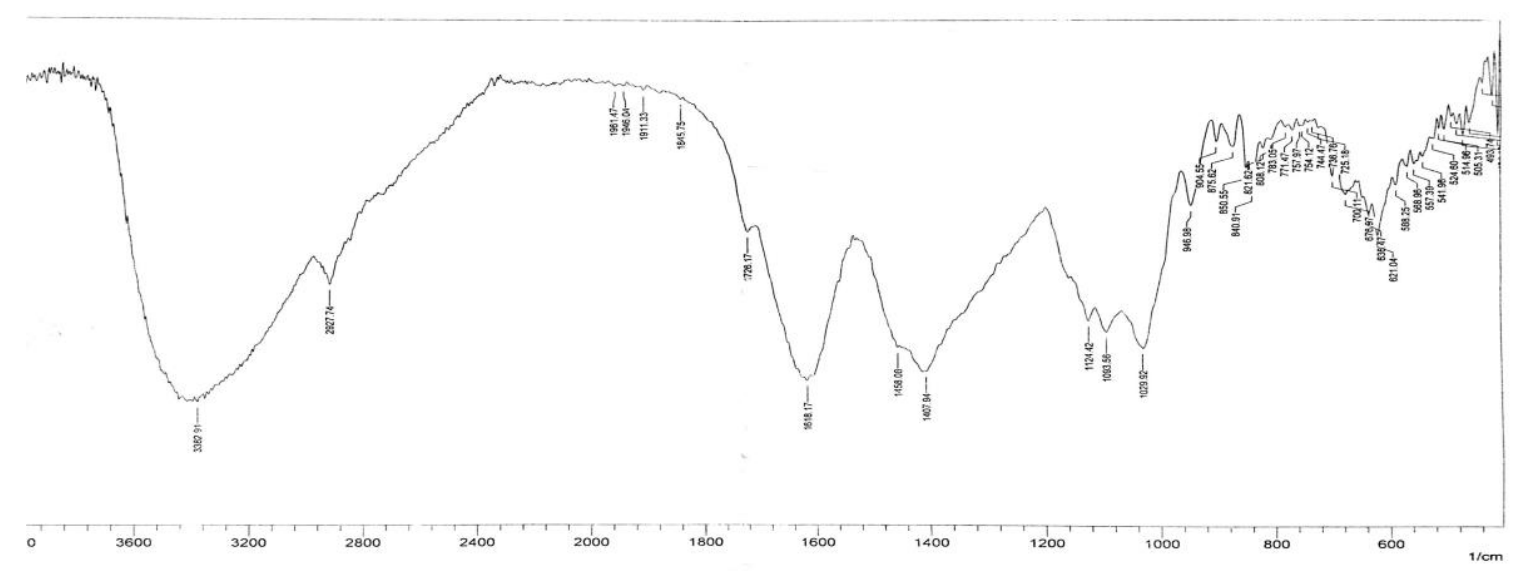

Figure 3. The FT-IR spectrum of the sodium alginate of $P$. pavonica (Sudan, Red Sea coast)

In T. ornata alginate FT-IR spectrum the following bands were recorded: $3423.41 \mathrm{~cm}^{-1}$, $2931.60 \mathrm{~cm}^{-1}, 1623.95 \mathrm{~cm}^{-1}, 1512.09 \mathrm{~cm}^{-1}, 1417.58 \mathrm{~cm}^{-1}, 1359.72 \mathrm{~cm}^{-1}, 1122.49 \mathrm{~cm}^{-1}, 1087.78$ $\mathrm{cm}^{-1}, 1033.77 \mathrm{~cm}^{-1}, 1026.0 \mathrm{~cm}^{-1}, 964.39 \mathrm{~cm}^{-1}, 875.62 \mathrm{~cm}^{-1}$, and $838.98 \mathrm{~cm}^{-1}$ (Figure 4).

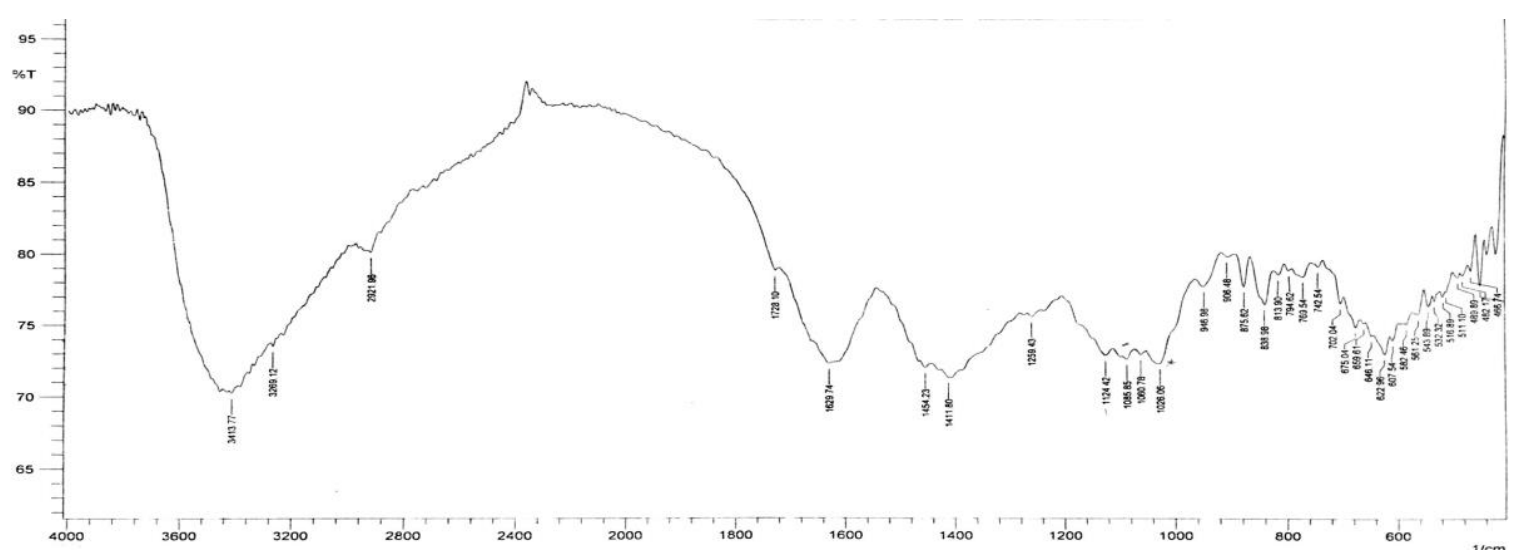

Figure 4. The FT-IR spectrum of the sodium alginate of T. ornata (Sudan, Red Sea coast)

Though, the alginate FT-IR spectra of the 4 seaweed species exhibited similar wavelength pattern, evident differences are perceptible between the fingerprint regions of the spectra (1400 $\mathrm{cm}^{-1}$ to $400 \mathrm{~cm}^{-1}$ ). All spectra exhibited the characteristics bands of alginate $[16,18,22]$. For instance the bands associated with stretching vibrations of $\mathrm{O}-\mathrm{H}$ bonds of alginate that appears in the range of $3000-3600 \mathrm{~cm}^{-1}$ have been reported in all the present alginate spectra. Similarly, stretching vibrations of aliphatic C-H that are observed at $2900-2930 \mathrm{~cm}^{-1}$ were also detected here together with the bands around $1600 \mathrm{~cm}^{-1}$ and $1400 \mathrm{~cm}^{-1}$ which correspond to the carbonyl and carboxyl groups respectively. All the spectra showed a peak at 946.88 to $946.98 \mathrm{~cm}^{-1}$ which may belong to the mannuronic acid. Broadly, the alginates IR spectra of the tested species are in conformity with those reported for Sargassum species from the Indian coast [23] in particular with regard to the presence of peaks around 1728 to $1735 \mathrm{~cm}^{-1}$.

In this investigation, the bands appeared around 1025 and $1100 \mathrm{~cm}^{-1}$ in the fingerprint region of the alginate FT-IR spectrum were assumed to refer to the absorbance of mannuronic and guluronic acids respectively[24, 25]. The $\mathrm{M} / \mathrm{G}$ ratios of $D$. dichotoma (0.92), $H$. cuneiformis (0.97), and P. pavonica (0.93) were all slightly $\leq 1$ (Table 2) indicating that the content of mannuronic acid is slightly less than that of the of guluronic acid in the alginates of these species. This result corroborates with García-Ríos et al. [15] who reported that the alginates from the seaweed of the Mexico contained more mannuronic acid. For T. ornata the $\mathrm{M} / \mathrm{G}$ ratio was slightly greater than one (1.01) suggesting that the alginate of this alga may 
contain equal proportion of mannuronic and guluronic acids or the less mannuronic acid units are slightly greater than the guluronic acid ones.

Table 2. The M/G ratios of sodium alginate in D. dichotoma, $H$. cuneiformis, P. pavonica, and T. ornata from Sudan.

\begin{tabular}{lcc}
\hline No & Species name & Alginate M/G ratio \\
\hline 1 & Dictyota dichotoma & 0.92 \\
2 & Hormophysa cuneiformis & 0.97 \\
3 & Padina pavonica & 0.93 \\
4 & Turbinaria ornata & 1.01 \\
\hline
\end{tabular}

On a broad basis these results are in accord with the information on the alginate of tropical brown macroalgae [15] that has been reported to have low proportion of mannuronic acid than guluronic acid and consequently low $\mathrm{M} / \mathrm{G}$ ratio and viscosity. The $\mathrm{M} / \mathrm{G}$ ratio is an index of the nature of gels produced, therefore alginates with low $\mathrm{M} / \mathrm{G}$ ratio $(<1)$ correspond to high values of guluronic than mannuronic acid form brittle gels [12], whereas alginates with high $\mathrm{M} / \mathrm{G}$ ratio $(>1)$ due to low content of guluronic acid produce soft and elastic gels. The M/G ratio of Padina spp was found to be 0.85 [26] slightly lower than that of the present $P$. pavonica. The dissimilarity in $\mathrm{M} / \mathrm{G}$ ratio within species was attributed to variation in species age, extraction method, algal tissue, and geographical location [2, 27, 28].

\section{CONCLUSION}

The values of the parameters of the native alginates extracted from the Sudanese macroalgae are comparatively in conformity with values reported for some species from similar geographical region. These values indicated that the present biopolymer is of a potential with regard to pharmaceutical and industrial applications. It is worth to mention that some treatments applied during alginate extraction process have a significant bearing on enhancing the yield and the quality of the polymer. Further research should be carried out to test the effect of these treatments on the yield and characteristic of alginates from Sudanese materials.

\section{Declaration of Conflicting Interests and Ethics}

The authors declare no conflict of interest. This research study complies with research publishing ethics. The scientific and legal responsibility for manuscripts published in IJSM belongs to the author(s).

\section{Orcid}

\section{Nahid Abdel Rahim Osman (iD https://orcid.org/0000-0001-6069-3396}

\section{REFERENCES}

[1]. Gupta, S., and Abu-Ghannam, N. (2011). Bioactive potential and possible health effects of edible brown seaweeds. Trends in Food Science \& Technology, 22, 315-326.

[2]. Masuelli, M.A., Illanes, C.O. (2014). Review of the characterization of sodium alginate by intrinsic viscosity measurements. Comparative analysis between conventional and single point methods. International Journal of BioMaterials Science and Engineering, 1(1), 111.

[3]. Rhein-Knudsen, N., Ale, M.T., Meyer, A.S. (2015). Seaweed Hydrocolloid Production: An Update on Enzyme Assisted Extraction and Modification Technologies. Mar. Drugs, 13, 3340-3359.

https://doi.org/10.3390/md13063340 
[4]. Hernande-Carmona, G. (2013). Conventional and alternative technologies for the extraction of algal polysaccharides. In: Functional Ingredients from Algae for Food and Naturaceuticals. Woodhead Publishing Limited.

[5]. Szekalska, M., Pucilowska, A., Szymanska, E., Ciosek, P., Winnicka, K. (2016). Alginate: current use and future perspectives in pharmaceutical and biomedical applications. International Journal of Polymer Science, 2016, ID: 7697031. https://doi.org/10.1155/2016/7697031

[6]. Lee, K.Y., and Mooney, D.J. (2012). Alginate: properties and biomedical applications. Prog Polym Sci., 37 (1), 106-126. https://doi.org/10.1016/j.progpolymsci.2011.06.003

[7]. Nalamothu, N., Potluri, A., Muppalla, M. B. (2014). Review on marine alginates and its applications. Indo American Journal of Pharm Research, 4 (10), 4006-4015.

[8]. Guarino, V., Caputo, T., Altobelli, R., and Luigi Ambrosio, L. (2015). Degradation properties and metabolic activity of alginate and chitosan polyelectrolytes for drug delivery and tissue engineering applications. AIMS Materials Science, 2(4), 497-502, https://doi.org/10.3934/matersci.2015.4.497

[9]. Parreidt, T. S., Müller, K., Schmid, M. (2018). Alginate-Based Edible Films and Coatings for Food Packaging Applications. Foods, 7(170). https://doi.org/10.3390/foods71001 70

[10]. Silva, T.L., Vidart, J.M., Silva, M.G., Gimenes, M.L., Vieira, M.G. (2018). Chapter 4 Alginate and Sericin : Environmental and Pharmaceutical Applications. In: Shalaby, E. (edi). Biological Activities and Application of Marine Polysaccharides.

[11]. AOAC. (1990). Official Methods of Analysis, $16^{\text {th }}$ ed. Association of official Analytical Chemists, Washington, DC.

[12]. Torres, M.R., Sousa, A.P.A., Filho, E.A.T.S., Melo, D.F., Feitosa, J.P.A., Paulab, R.C.M., Limaa, M.G.S. (2007). Extraction and physicochemical characterization of Sargassum vulgare alginate from Brazil. Carbohydr Res., 342, 2067-2074.

[13]. Rochas, C., Lahaye, M., Yaphye, W. (1986). Sulfate content of carrageenan and agar determined by infrared spectroscopy. Botanica Marina., 29, 335-340.

[14]. Deyab, M.A., El-Katony, T.M., El-Adl M.F., Ward, F.M. (2017). Temporal variation in chemical composition of Dictyota dichotoma (Hudson) J.V. Lamouroux (Dictyotales, Phaeophyceae) from Red Sea Coast, Egypt. Journal of Coastal Life Medicine, 5(4), 149155.

[15]. García-Ríos, V., Ríos-Leal, E., Robledo, D., Freile-Pelegrin1, Y. (2012). Polysaccharides composition from tropical brown seaweeds. Phycological Research, 60, 305-315.

[16]. Latifi, A.M., Nejad, E.S., Babavalian, H. (2015). Comparison of Extraction Different Methods of Sodium Alginate from Brown Alga Sargassum sp. Localized in the Southern of Iran. Journal of Applied Biotechnology Reports, 2(2), 251-255.

[17]. Widyastuti, S. (2009). Alginate content of the seaweeds grown in coastal zone of Lombok extracted by two extraction methods. Jurnal Teknologi Pertanian, 10(3), 144-152.

[18]. Subramanian, V., Ganapathy, K., and Dakshinamoorthy, B. (2015). FT-IR, ${ }^{1}$ H- NMR and ${ }^{13} \mathrm{C}$ - NMR spectroscopy of alginate extracted from Turbinaria decurrens (Phaeophyta). World Journal of Pharmacy and Pharmaceutical Sciences, 4(12), 761-771.

[19]. Hernandez-Carmona, G., McHugh, D.J., Lopez-Gutierrez, F. (1999). Pilot plant scale extraction of alginate from Macrocystis pyrifera. 2. Studies on extraction conditions and methods of separating the alkaline-insoluble residue. J. Appl. Phycol., 11, 493-502.

[20]. Sachan, N.K., Pushkar, S., Jha, A., Bhattcharya, A. (2009). Sodium alginate: the wonder polymer for controlled drug delivery. Journal of Pharmacy Research, 2(8),1191-1199.

[21]. Nahar, K., , Hossain, M. K., Khan, T. A. (2017). Alginate and its versatile application in drug delivery. J. Pharm. Sci. \& Res., 9(5), 606-617. 
[22]. Torres, M.L., Cortizo, A.M., Oberti, T.G., Fernández, J.M. (2016). Characterization of commercial and algae (Undaria pinnatifida) extracted sodium alginate for future application in bone tissue engineering. Colaob, 24 to 27 de Agosto de 2016 Foz do Iguacu. PR.

[23]. Ganapathi, K., Subramanian, V., Mathan, S. (2013). Bioactive potentials of brown seaweeds, Sargassum myriocystum J. Agardh, S. plagiophyllum C.Agardh and $S$. ilicifolium (Turner) J. Agardh. Int. Res J Pharm. App Sci., 3(5), 105-111.

[24]. Filippov, M.P., and Kohn, B.R. (1974). Determination of composition of alginates by infrared spectroscopic method. Chem. Zvesti, 28(6), 817-819.

[25]. Pereira, L., Sousa, A., Coelho, H., Amado, A.M., Ribeiro-Claro, P.J.A. (2003). Use of FT-IR, FT-Raman and ${ }^{13} \mathrm{C}-\mathrm{NMR}$ spectroscopy for identification of some seaweed phycocolloids. Biomolecular Engineering, 20, 223-228.

[26]. Omar, S., Ahmad, N., Ahmad, F. (1988). Composition of Alginates from Brown Seaweeds, Sargassum and Padina spp. Pertanika, 11(1), 79-85.

[27]. Murillo, Á., and Hernández, C. (2007). Monomer composition and sequence of sodium alginate extracted at pilot plant scale from three commercially important seaweeds from Mexico. J. Appl Phycol, 19, 545-548. https://doi.org/10.1007/s10811-007-9168-5

[28]. Fertah, M., Belfkira, A., Dahmane, E., Taourirte, M., Brouillette, F. (2017). Extraction and characterization of sodium alginate from Moroccan Laminaria digitata brown seaweed. Arabian Journal of Chemistry, 10, 3707-3714. 